\title{
Buckling Analysis of Steel Semi-Spherical Shells with Square Cutout under Axial Compression
}

\author{
H. Torabi ${ }^{\mathrm{a}, 1}$ and M. Shariati ${ }^{\mathrm{b}}$ \\ a Young Researchers Club, Mashhad Branch, Islamic Azad University, Mashhad, Iran \\ ${ }^{\mathrm{b}}$ Mechanical Department, Shahrood University of Technology, Shahrood, Iran \\ 1 Torabi.mech87@gmail.com
}

УДК 539.4

\section{Расчет потери устойчивости стальных полусферических оболочек с квадратным вырезом, подвергнутых осевому сжатию}

\author{
Х. Тораби ${ }^{\mathrm{a}, 1}$, М. Шариати ${ }^{6}$

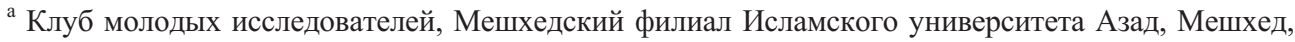 \\ Иран \\ ${ }^{\sigma}$ Факультет механики Шахрудского технологического университета, Шахруд, Иран
}

Выполнены численный расчет потери устойчивости стальных тонкостенных полусферических оболочек с квадратным вырезом, подвергнутых осевому сжатию, и сравнительный анализ полученных расчетных данных с экспериментальными. При этом использовались три варианта приложения к образиам вертикальных сжимающих нагрузок: через жесткую плоскую пластину; через жесткие балки с ториами ичилиндрической и сферической формьл. Определялось влияние отномений ширины квадратного выреза к его вертикальному положению в оболочке $(a / H)$ и толщины оболочки кее диаметру (t/D) на среднее значение критической нагрузки, при которой происходит потеря устойчивости полусферической оболочки. Конечноэлементные модели реализованы с помощью программного пакета ABAQUS для нелинейного расчета потери устойчивости, а соответствующче экспериментальные результать получень с использованием сервогидравлической испытательной установки INSTRON 8802. Сравнительный анализ результатов, полученных двумя расчетными методами, показал тесную корреляцию между экспериментальными и численными нелинейными расчетными даннымин.

Ключевые слова: потеря устойчивости, полусферическая оболочка, квадратный вырез, метод конечных элементов, эксперимент.

Introduction. Thin walled semi-spherical shells usually are extensively used in many types of structures due to their energy absorbing capacity. They are subjected to various combinations of loading. The most critical load which challenges the stability of thin shells is axial compression. The buckling behavior of these shells gives rise to their critical design application, such as nose cone of aircraft, lunch vehicles and ballistic missiles due to high energy absorbing capacity. The major deformation of rigid plastic semi-spherical shells which were compressed between two rigid plates was first studied by Updike [1] which led to proposal of an analytical model. The computation was restricted to the compression up to about one-tenth of the shell radius. Deformation patterns on semi-spherical shells of $R / t$ ratios between 36 to 420 were studied experimentally and analytically by Kitching et al. [2]. De Oliveira and Wierzbicki [3] did similar study on crushing analysis of rotationally symmetric plastic shells. There was also a quasi-static study on semi-spherical shells of 
$R / t$ ratios between 36 to 420 by Kinkead et al. [4] in which the results were compared with previous studies. Gupta et al. [5] performed experiments on metallic semi-spherical shells of $R / t$ ratios ranging between 15 to 240 and the three levels of deformation, namely: local flattening, inward dimpling, and multiple lobes were studied. A two-dimensional numerical analysis for the semi-spherical shells under axial impact was presented by Gupta and Venkatesh [6]. In this study, a very good correlation was observed between numerical simulation and experimental results in buckling behavior related to first mode jumping from local flattening to inward dimpling.

Shariati and Mahdizadeh Rokhi [7] studied the effect of position of elliptical cutouts with identical dimensions on the buckling and postbuckling behavior of cylindrical shells with different diameters and lengths and developed several parametric relationships based on the 3 numerical and experimental results using the Lagrangian polynomial method. Also, Shariati and Mahdizadeh Rokhi [8] performed a similar numerical study using ABAQUS software to investigate the response of steel cylindrical shells with different lengths and diameters, including elliptical cutout subjected to bending moment. They presented some relations for finding of buckling moment of these structures.

Gupta [9] performed another study in which the semi-spherical shells of $R / t$ ratios between 26 and 45 were analyzed experimentally and computationally. In experiments, all the spherical shells were found to collapse in an axsymmetric mode.

Shariati and Mahdizadeh Rokhi [10] investigated numerical simulation and analysis of steel cylindrical shells with various diameters and lengths having an elliptical cutout, subjected to axial compression. In this work, they examined the influence of the cutout size, cutout angle and the shell aspect ratios $(L / D$ and $D / t)$ on the pre-buckling, buckling, and post-buckling responses of the cylindrical shells. In addition, Shariati and Mahdizadeh Rokhi [11] did another work in which simulation and analysis of steel cylindrical shells of various lengths, including quasi-elliptical cutout, subjected to axial compression load were systematically carried out using the finite element method. The investigation examined the influence of the cutout location and the shell aspect ratio $(L / D)$ on the buckling, and the post-buckling responses of the cylindrical shells.

Shariati and Allahbakhsh [12] studied the buckling and postbuckling of steel thinwalled semi-spherical shells under different loadings, both experimentally and numerically. Various vertical compression loadings were applied to specimens using the following methods: a rigid flat plate and some rigid bars with circular, square and spherical cross sections, a rigid tube, a plate with a hole, and an indented tube.

In this work, efforts are made to determine the effect of the position and size of square cutouts on the buckling behavior of semi-spherical shells. Various vertical compression loadings are applied to specimens and the mean load are obtained for each other. For this purpose, finite element (FE) models of semi-spherical shells with a square cutout having different shell aspect ratios $(t / D)$ are generated. These FE models are analyzed using ABAQUS linear and nonlinear analysis. In addition, several buckling tests were performed using an INSTRON 8802 servo-hydraulic machine and the results were compared with the results of the finite element method. A very good correlation between experiments and numerical simulations was observed. Finally, based on the experimental and numerical results, formulas are presented for the computation of the buckling load in such structures.

1. Numerical Analysis Using the Finite Element Method. The numerical simulations were carried out using the finite element software ABAQUS 6.4-PR11.

\subsection{Geometry and Mechanical Properties of the Shells.}

In this study, thin-walled semi-spherical shells with four different thickness $(t=0.7$, $0.8,1.0$, and $1.2 \mathrm{~mm}$ ) were analyzed. A square geometry was selected for cutouts that were created in the specimens. Figure 1 illustrates the geometry of the specimens. According to this figure, parameters $(D, d, t$, and $h)$ show the upper diameter, lower diameter, thickness and height of the semi-spherical shells, respectively. In Fig. 1, parameter $a$ shows the side 
length of the square cutout, parameter $H$ is the distance between the center of the cutout and the lower edge of the shell, parameter $L$ is the arc length, and $P$ and $A$ are the perimeter and area of the cutout, respectively. The values of geometric parameters for the semi-spherical shells were $d=102 \mathrm{~mm}, D=25 \mathrm{~mm}$, and $h=52 \mathrm{~mm}$. The specifications of square cutouts are presented in Table 1.

$\mathrm{T}$ a $\mathrm{b} 1 \mathrm{e} 1$

Specification for Square Cutouts

\begin{tabular}{|c|c|c|c|c|c||}
\hline $\begin{array}{c}\text { Model } \\
\text { specification }\end{array}$ & $\begin{array}{c}\text { Area }(A), \\
\mathrm{mm}^{2}\end{array}$ & $\begin{array}{c}\text { Perimeter }(P), \\
\mathrm{mm}\end{array}$ & $\begin{array}{c}\text { Arc length }(L), \\
\mathrm{mm}\end{array}$ & $R_{3}=\frac{P}{H}$ & $R_{4}=\frac{a}{H}$ \\
\hline H8-a10 & 100.42 & 40.15 & 10.06 & 5.019 & 1.2500 \\
H16-a10 & 101.03 & 40.31 & 10.14 & 2.519 & 0.6250 \\
H24-a10 & 105.43 & 41.21 & 10.59 & 1.717 & 0.4167 \\
H40-a10 & 140.01 & 48.00 & 13.97 & 1.200 & 0.2500 \\
H16-a20 & 408.72 & 81.13 & 20.42 & 5.071 & 1.2500 \\
H24-a20 & 429.46 & 83.20 & 21.43 & 3.467 & 0.8330 \\
H32-a20 & 472.24 & 88.01 & 23.79 & 2.750 & 0.6250 \\
H40-a20 & 638.03 & 106.60 & 32.80 & 2.667 & 0.5000 \\
H16-a30 & 936.50 & 123.05 & 30.99 & 7.691 & 1.8750 \\
H24-a30 & 990.20 & 127.41 & 33.06 & 5.309 & 1.2500 \\
\hline
\end{tabular}
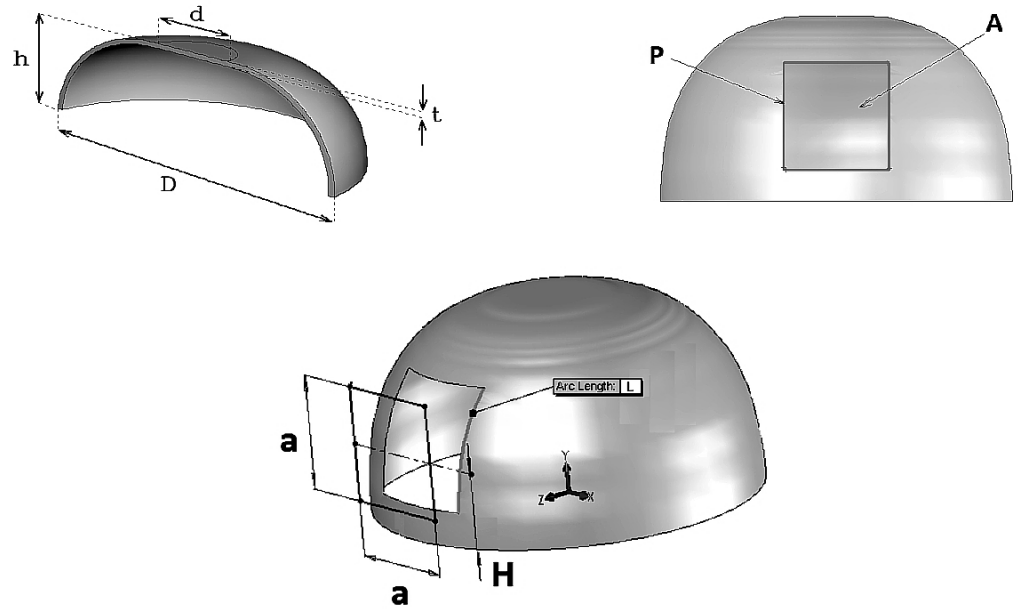

Fig. 1. Geometry of specimens and cutouts.

Specimens were nominated as follows: H24-t0.8-a10. The number following $t$ shows the thickness value of the specimen. Furthermore, the numbers following $H$ and $a$ show the distance between the center of the cutout and the lower edge of the shell and the side value of the square cutout, respectively.

The semi-spherical shells used for this study were made of mild steel alloy. The mechanical properties of this steel alloy were determined according to ASTM E8 standard [13], using the INSTRON 8802 servo-hydraulic machine. The stress-strain and stressplastic strain curves can be found in [7]. The value of elasticity module was computed as $E=150 \mathrm{GPa}$ and the value of yield stress was obtained as $\sigma=404 \mathrm{MPa}$. Furthermore, the value of Poisson's ratio was assumed to be $v=0.33$. 
1.2. Boundary Conditions. For applying boundary conditions on the bottom edges of the semi-spherical shells, a rigid plate was attached to the bottom edges of the semispherical shells. To analyze their buckling numerically, the specimens were subjected to axial load similar to what was done in the experimental tests. In this process, a displacement was applied to the center of the upper plate, or bar.

Additionally, all degrees of freedom in the lower plate and all degrees of freedom in the upper plate, or bar, except in the direction of longitudinal axis, were constrained.

1.3. Element Formulation of the Specimens. In this study, the nonlinear element S8R5, which is an eight-node element with six degrees of freedom per node and is suitable for analysis of thin shells, was used. The nonlinear element was used for the analysis of the shells, and the results were compared with each other. For rigid plate or bar the element R3D4 was used. A friction coefficient of 0.1 has been taken. The effect of friction coefficient ranged from 0.08 to 0.12 and affected results by less $1 \%$ [6].

1.4. Numerical Process. To analyze the buckling of semi-spherical shells, two analysis methods, linear eigenvalue analysis and geometric nonlinear, were employed using the "Buckle" and "Static Riks" solvers respectively. For more information about these FE methods you can refer to Shariati and Allahbakhsh [12], Lee et al. [14] and ABAQUS user manual [15].

2. Results of Numerical Analysis. In this Section, the numerical results of the buckling analysis of semi-spherical shells with square cutouts of different sizes and locations, using the finite element method, are presented. Four different shell thicknesses of $1.2,1.0,0.8$, and $0.7 \mathrm{~mm}$ were analyzed.

2.1. Loading by a Rigid Plate. In this paper, for comparison, the energy absorption capacity of specimens is a criteria that defines the mean collapse load. Mean collapse load is calculated by dividing the area of under the load-displacement curve by the displacement of the upper rigid plate. During loading by a rigid plate, it is seen that the collapse is initiated by the formation of an axisymmetric ring at the smaller end. With further compression, the mechanism of collapse changes. At this stage, its propagation is due to the formation of stationary plastic hinges and internal lobes that is in contact with the top plate. The number of internal lobes depends on the cutout size and location. It is clearly noticeable as the slope of the load-deformation curves changes appreciably as shown in Fig. 2.
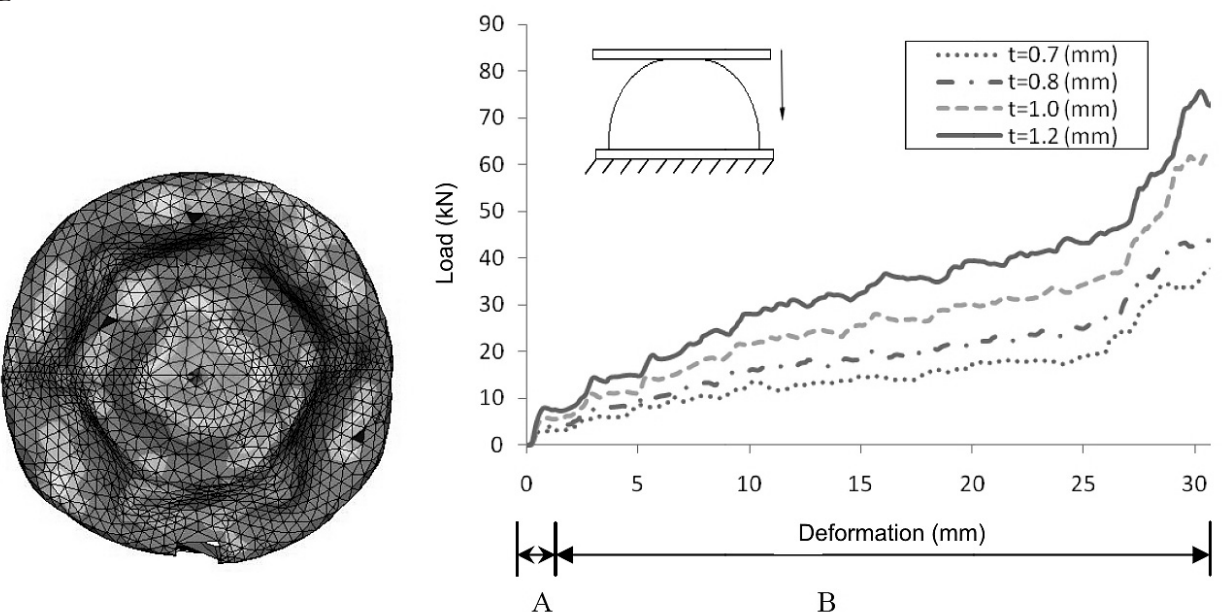

Fig. 2. Load-deformation curves of specimen H24-a10 and wall thickness for a semi-spherical shell with thickness of $0.7 \mathrm{~mm}$ in loading by a rigid plate. (Here and in Fig. 3: $A=$ zone representing formation of an axisymmetric ring at the smaller end and $B=$ zone representing formation of an axisymmetric inward dimpling.) 
2.2. Loading by Different Bars. In this section, the effect of loading conditions is considered. Therefore, some semi-spherical shells with a diameter equal to the small diameter of the semi-spherical shells $(d=25 \mathrm{~mm})$ are loaded by a circular bar. Semispherical shells are also loaded by a semi-spherical end.

Figure 3 shows the load-deformation curves that were obtained for the specimen H32-a20 with various thicknesses in loading by a circular cross section bar. During loading with a circular cross section, only the first mode is observed from the formation of an axisymmetric ring towards inward dimpling. As it can be observed increasing the thickness of shell will lead to higher values of mean collapse load. The primary part of the curve in loading by circular cross section bar is linear shown.

Table 2 present the results from numerical simulations with the rigid plate (RP) and bar with a circular cross section (CC).

T a b 1 e 2

Summary of Numerical Analysis for Semi-Spherical Shells Including a Square Cutout in Loading with Rigid Plate and Circular Cross Section Bar

\begin{tabular}{|c|c|c|c|c|c|c|c|c|c|}
\hline \multirow{3}{*}{$\begin{array}{c}\text { Model } \\
\text { specification }\end{array}$} & \multirow{3}{*}{$\begin{array}{l}\text { Deformation } \\
\text { height } \\
(\mathrm{mm})\end{array}$} & \multicolumn{8}{|c|}{ Mean collapse load $(\mathrm{kN})$} \\
\hline & & \multicolumn{2}{|c|}{$t=0.7 \mathrm{~mm}$} & \multicolumn{2}{|c|}{$t=0.8 \mathrm{~mm}$} & \multicolumn{2}{|c|}{$t=1.0 \mathrm{~mm}$} & \multicolumn{2}{|c|}{$t=1.2 \mathrm{~mm}$} \\
\hline & & $\mathrm{RP}$ & $\mathrm{CC}$ & $\mathrm{RP}$ & $\mathrm{CC}$ & $\mathrm{RP}$ & $\mathrm{CC}$ & $\mathrm{RP}$ & $\mathrm{CC}$ \\
\hline Perfect & 28 & 14.85 & 3.82 & 17.84 & 4.67 & 23.95 & 6.47 & 30.79 & 8.97 \\
\hline H8-a10 & 28 & 13.28 & 3.29 & 16.21 & 4.73 & 22.90 & 6.65 & 30.24 & 8.60 \\
\hline H16-a10 & 28 & 13.32 & 3.50 & 16.39 & 4.37 & 22.88 & 6.20 & 30.11 & 8.28 \\
\hline $\mathrm{H} 24-\mathrm{a} 10$ & 28 & 13.42 & 3.44 & 17.32 & 4.28 & 23.51 & 6.12 & 30.07 & 8.16 \\
\hline $\mathrm{H} 40-\mathrm{a} 10$ & 28 & 13.72 & 3.60 & 16.67 & 4.36 & 22.79 & 6.09 & 29.51 & 8.10 \\
\hline Perfect & 23 & 13.06 & 3.41 & 14.89 & 4.17 & 20.18 & 5.75 & 26.05 & 7.98 \\
\hline H16-a20 & 23 & 11.58 & 3.12 & 14.40 & 3.88 & 20.78 & 5.53 & 26.81 & 7.38 \\
\hline $\mathrm{H} 24-\mathrm{a} 20$ & 23 & 12.04 & 3.11 & 14.49 & 3.87 & 19.66 & 5.51 & 25.36 & 7.36 \\
\hline H32-a20 & 23 & 10.60 & 2.83 & 12.80 & 3.55 & 17.90 & 5.11 & 23.30 & 6.88 \\
\hline $\mathrm{H} 40-\mathrm{a} 20$ & 23 & 10.33 & 2.34 & 12.41 & 2.90 & 17.32 & 4.14 & 23.44 & 5.85 \\
\hline Perfect & 21 & 12.37 & 3.24 & 15.69 & 3.97 & 21.22 & 5.44 & 27.36 & 7.68 \\
\hline H16-a30 & 21 & 9.22 & 3.11 & 12.86 & 3.68 & 17.81 & 5.22 & 23.22 & 7.25 \\
\hline H24-a30 & 21 & 10.67 & 2.94 & 13.67 & 3.63 & 18.24 & 5.10 & 23.24 & 6.84 \\
\hline
\end{tabular}
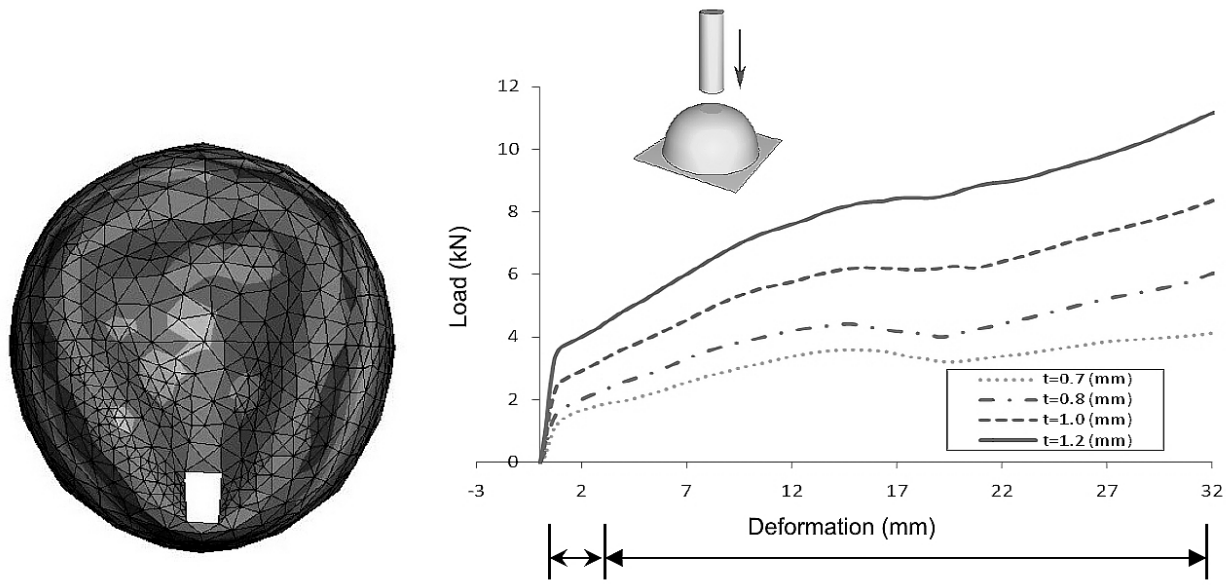

A

B

Fig. 3. Load-deformation curves of specimen H32-a20 and wall thickness for a semi-spherical shell with thickness of $0.7 \mathrm{~mm}$ in loading by a circular cross section bar. 
Figure 4 shows loading by a rigid bar with a semi-spherical cross section. As for loading by a circular bar, it is seen that the primary part of the curve is linear. Also, the formation of an axisymmetric ring is not observed and a mode jump is observed, namely, from inward dimpling to formation of stationary plastic hinges.

Table 3 presents the results from numerical simulations for the bar with a semispherical cross section.

T a b 1 e 3

Summary of Numerical Analysis for Semi-Spherical Shells Including a Square Cutout in Loading with a Spherical Cross Section Bar

\begin{tabular}{|c|c|c|}
\hline Model specification & Deformation $(\mathrm{mm})$ & Mean collapse load $(\mathrm{kN})$ \\
\hline H16-t0.7-a10 & 25 & 2.99 \\
H24-t0.7-a10 & 25 & 2.92 \\
H40-t0.7-a10 & 25 & 3.71 \\
H16-t0.7-a20 & 20 & 2.56 \\
H24-t0.7-a20 & 20 & 2.57 \\
H32-t0.7-a20 & 20 & 2.99 \\
H40-t0.7-a20 & 20 & 2.53 \\
H16-t0.7-a30 & 35 & 4.82 \\
H24-t0.7-a30 & 35 & 3.14 \\
\hline
\end{tabular}

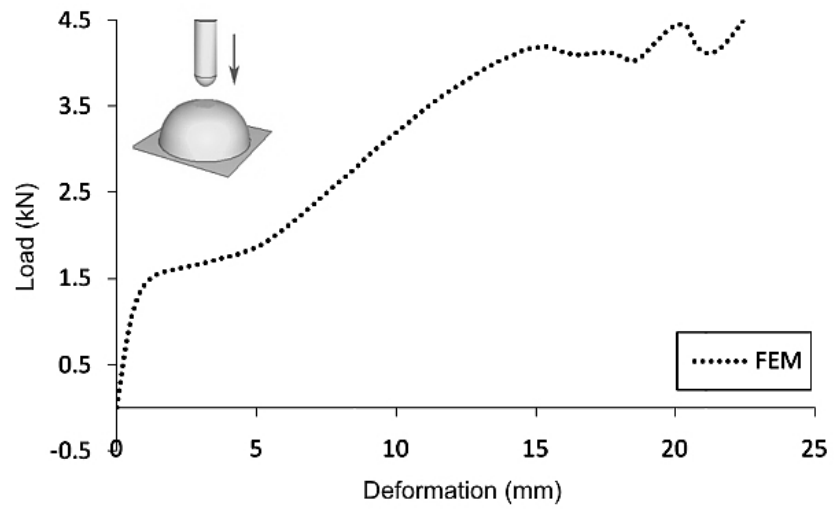

Fig. 4. Load-deformation curves of specimen H32-t0.7-a20 and wall thickness for a semi-spherical shell in loading by a spherical cross section bar (SPC).

2.3. Loading by a Rigid Tube. In this section, the loading is carried out by a rigid tube with thickness of $5 \mathrm{~mm}$. Figure 5 shows the load-deformation curve and wall thickness for the H40-t0.7-a10 which has been loaded by tube with two $\theta$ values. It is clear that with decreasing $\theta$, the mean collapse load decreases.

\subsection{The Effects of Cutout Size, $a / H$ and $t / D$ Ratios.}

2.4.1. Analysis of the Effect of Change in Cutout Height on the Mean Collapse Load. To study the effect of a change in cutout height on the buckling load of semi-spherical shells, cutouts with constant sides $(10,20$, and $30 \mathrm{~mm})$ were created in different positions of shells. Then, with changing the height of the cutouts from 8 to $40 \mathrm{~mm}$, the change in mean collapse load was studied. The results of the analysis are shown in Table 2.

2.4.2. Analysis of the Effect of Change in Cutout Side on the Mean Collapse Load. In this section, the effect of changing the cutout side on the mean collapse load of semi-spherical shells is studied. For this reason, cutouts with fixed height $(8,16,24,32$, 


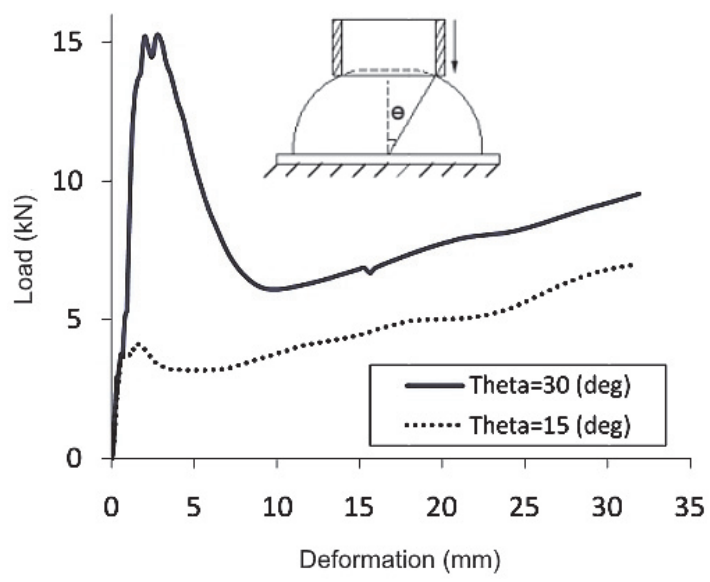

Fig. 5. Load-deformation curves for the specimen H40-t0.7-a10 at loading by rigid plate with a hole at $\theta=15$ and $30^{\circ}$.

and $40 \mathrm{~mm}$ ) were created in different positions of shells. Then, with changing the side of the cutouts from 10 to $30 \mathrm{~mm}$, the change in mean collapse load was studied. The results of this analysis are also presented in Table 2. The results show when the cutout height is constant, an increase in cutout side decreases the mean collapse load. It is evident from Table 2 that an increase in the cutout side when cutout height is constant causes a considerable reduction in the mean collapse load.

3. Experimental Verification. Experimental tests were conducted on a large number of specimens, in order to confirm some of the cases analyzed in the numerical simulations. As shown in Fig. 6, for these tests a servo-hydraulic INSTRON 8802 machine was used. The specimens were constrained by steel sleeve fixtures inserted at both ends, which models the fixed-fixed boundary condition used in the finite element simulations (Fig. 6). Various specimens were tested for each loading and almost identical results were obtained compared to those obtained from the numerical simulations. The experimental results are compared to numerical findings in Tables 4 and 5 in loading by the rigid plate and circular cross section bar, respectively. The comparison shows that there is a little difference between the two sets of data.

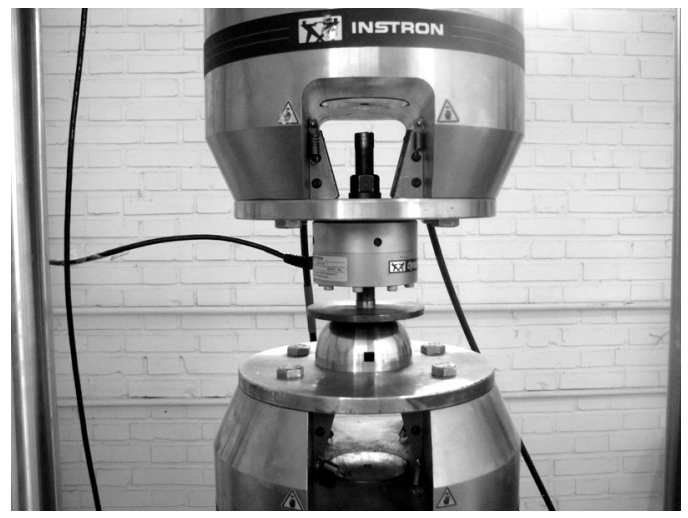

Fig. 6. A servo-hydraulic INSTRON 8802 machine in loading on semi-spherical shell including a square cutout by rigid plate.

The load-deformation curves and deformed shape of specimens in the buckling and postbuckling states in numerical and experimental tests in loading by the rigid plate and 
$\mathrm{T}$ a b 1 e 4

Comparison of the Experimental and Numerical Results for Semi-Spherical Shells Including a Square Cutout in Loading with a Rigid Plate

\begin{tabular}{||c|c|c|c|c||}
\hline \multirow{2}{*}{$\begin{array}{c}\text { Model } \\
\text { specification }\end{array}$} & $\begin{array}{c}\text { Deformation } \\
\text { height }(\mathrm{mm})\end{array}$ & \multicolumn{2}{|c||}{ Mean collapse load $(\mathrm{kN})$} & \multirow{2}{*}{$\frac{\left|F_{\text {num }}-F_{\text {exp }}\right|}{F_{\text {num }}} \cdot 100 \%$} \\
\cline { 3 - 4 } & 20 & 10.66 & 10.72 & 0.56 \\
H16-a10 & 20 & 10.65 & 10.75 & 0.93 \\
H24-a10 & 20 & 9.99 & 10.85 & 7.93 \\
H40-a10 & 20 & 10.44 & 10.63 & 1.79 \\
H16-a20 & 20 & 10.80 & 11.17 & 3.31 \\
H24-a20 & 20 & 10.04 & 9.90 & 1.41 \\
H32-a20 & 20 & 8.30 & 8.37 & 0.84 \\
H40-a20 & 20 & 9.74 & 9.07 & 7.39 \\
H16-a30 & 20 & 8.41 & 9.20 & 8.59 \\
H24-a30 & 20 & Numerical & \\
\hline
\end{tabular}

$\mathrm{T}$ a b 1 e 5

Comparison of the Experimental and Numerical Results for Semi-Spherical Shells Including a Square Cutout in Loading with a Circular Cross Section Bar

\begin{tabular}{||c|c|c|c|c||}
\hline \multirow{2}{*}{$\begin{array}{c}\text { Model } \\
\text { specification }\end{array}$} & \multirow{2}{*}{$\begin{array}{c}\text { Deformation } \\
\text { height }(\mathrm{mm})\end{array}$} & \multicolumn{2}{|c|}{ Mean collapse load (kN) } & \multirow{2}{*}{$\frac{\left|F_{\text {num }}-F_{\text {exp }}\right|}{F_{\text {num }}} \cdot 100 \%$} \\
\cline { 3 - 4 } & 25 & 3.33 & 3.18 & 4.72 \\
\hline H8-a10 & 25 & 3.29 & 3.34 & 1.50 \\
H16-a10 & 25 & 3.16 & 3.30 & 4.24 \\
H24-a10 & 25 & 2.98 & 3.28 & 9.15 \\
H40-a10 & 25 & 3.10 & 3.26 & 4.91 \\
H16-a20 & 25 & 3.20 & 3.28 & 2.44 \\
H24-a20 & 25 & 2.76 & 2.89 & 4.50 \\
H32-a20 & 25 & 2.36 & 2.46 & 4.07 \\
H40-a20 & 25 & 3.04 & 3.22 & 5.59 \\
H16-a30 & 25 & 2.89 & 3.18 & 9.11 \\
H24-a30 & 25 & \\
\hline
\end{tabular}

circular cross section bar are compared in Figs. 7-15 and Fig. 16, respectively. It can be seen that the slope of linear part of the curves is higher in numerical analysis than in experimental results. This is maybe due to the presence of internal defects in the material which reduce the stiffness of the specimens in the experimental method, while the materials are assumed to be ideal in the numerical analyses.

Comparison of deformations resulted by numerical and experimental methods for the specimens shown in Fig. 16 in the buckling state, shows that almost identical results were obtained.

4. Empirical-Numerical Equations. Based on the numerical and experimental dimensionless mean collapse loads of shells, formulas are presented here using the Lagrangian polynomial for the computation of the mean collapse load of semi-spherical shells with square cutouts subject to axial compression. To get these formulas, surfaces were fitted to the dimensionless mean collapse load values using the Lagrangian polynomial method [16]. Value of $K_{\text {cutout }}$ is introduced as a mean collapse load reduction factor for semi-spherical shells with cutout (dimensionless mean collapse load), $\gamma=t / D$ and $\lambda=a / H$. 


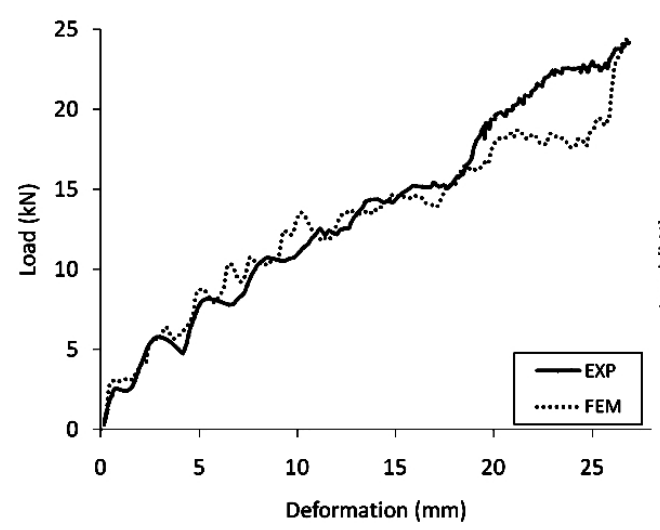

a

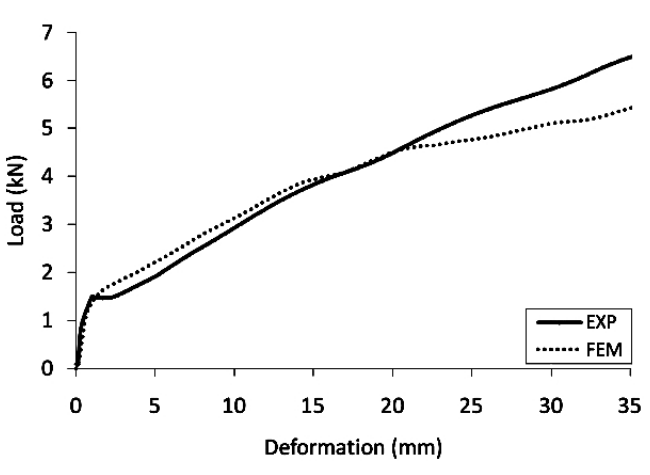

b

Fig. 7. Comparison of the experimental and numerical results for specimen H16-t0.7-a10 in loading with a rigid plate (a) and a rigid tube with a circular cross section (b).

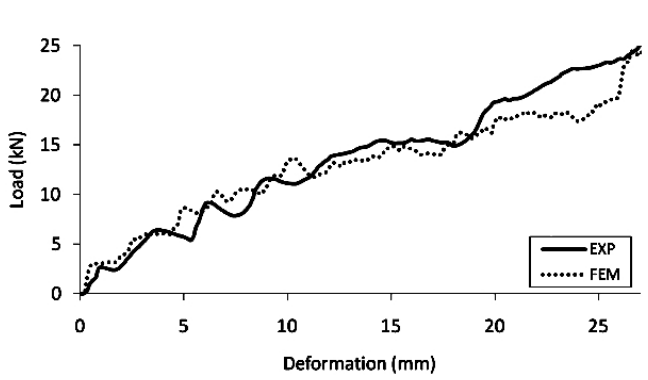

a

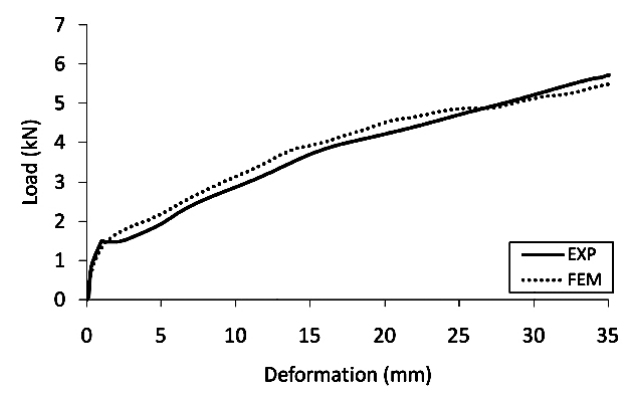

b

Fig. 8. Comparison of the experimental and numerical results for specimen H24-t0.7-a10 in loading with a rigid plate (a) and a rigid tube with a circular cross section (b).

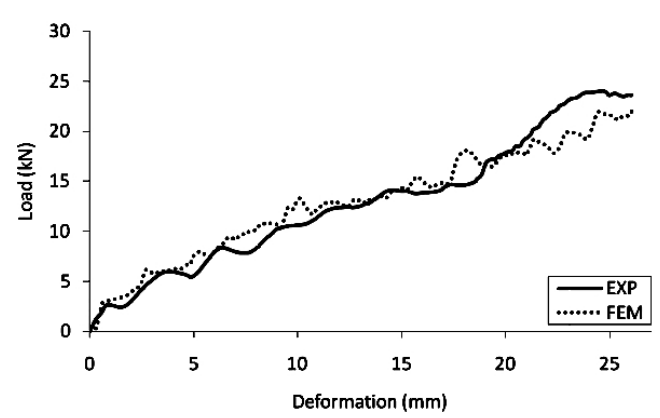

a

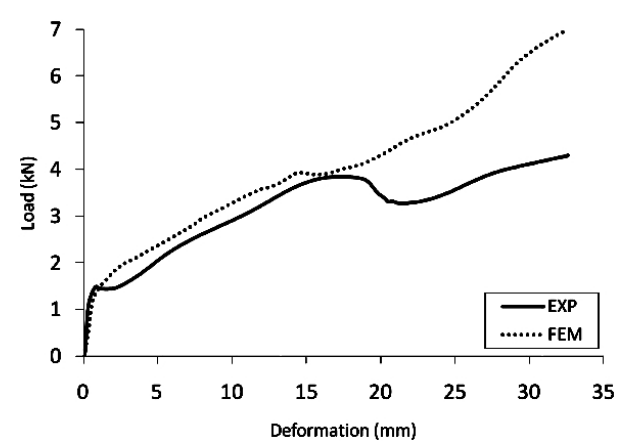

b

Fig. 9. Comparison of the experimental and numerical results for specimen H40-t0.7-a10 in loading with a rigid plate (a) and a rigid tube with a circular cross section (b).

Value of $K_{\text {cutout }}$ is defined according to Eq. (1):

$$
K_{\text {cutout }}=\frac{F_{\text {cutout }}}{F_{\text {perfect }}} \text {, }
$$




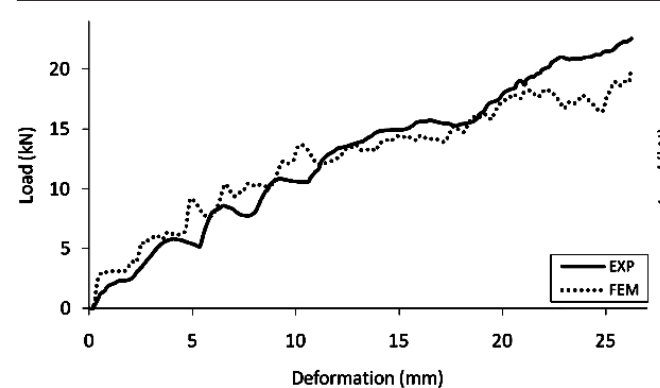

a

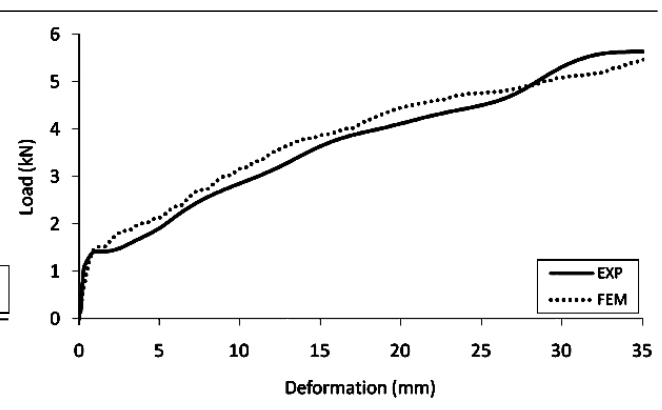

$\mathrm{b}$

Fig. 10. Comparison of the experimental and numerical results for specimen H16-t0.7-a20 in loading with a rigid plate (a) and a rigid tube with a circular cross section (b).

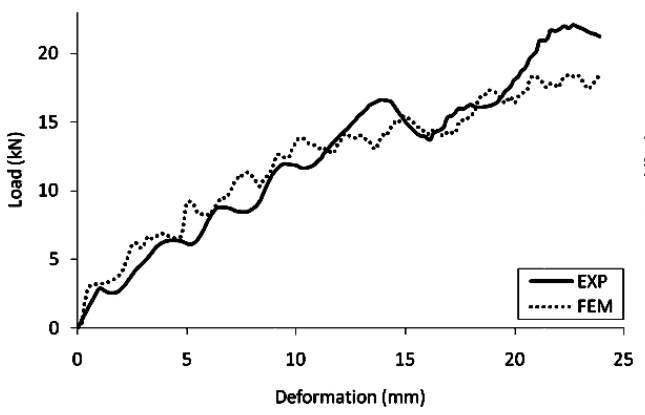

a

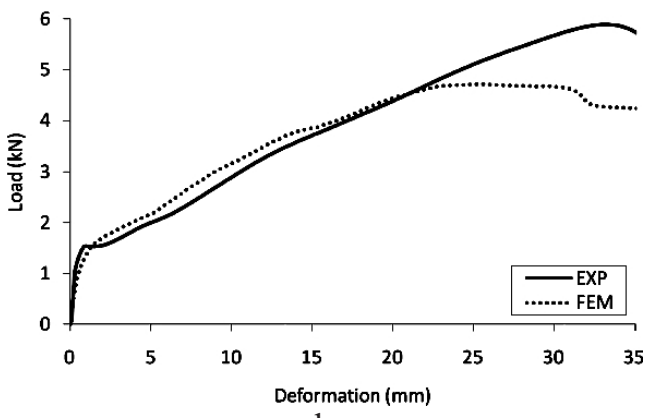

b

Fig. 11. Comparison of the experimental and numerical results for specimen H24-t0.7-a20 in loading with a rigid plate (a) and a rigid tube with a circular cross section (b).

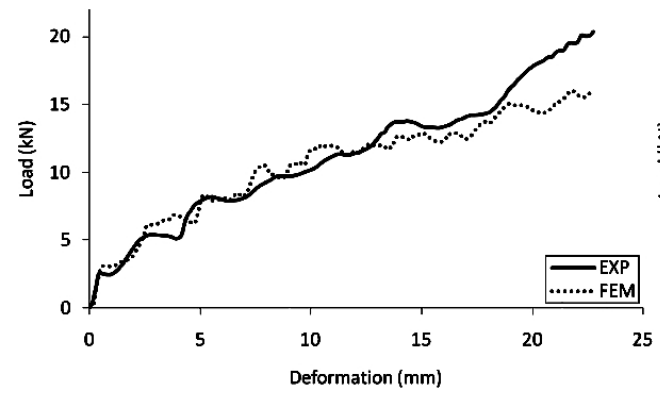

a

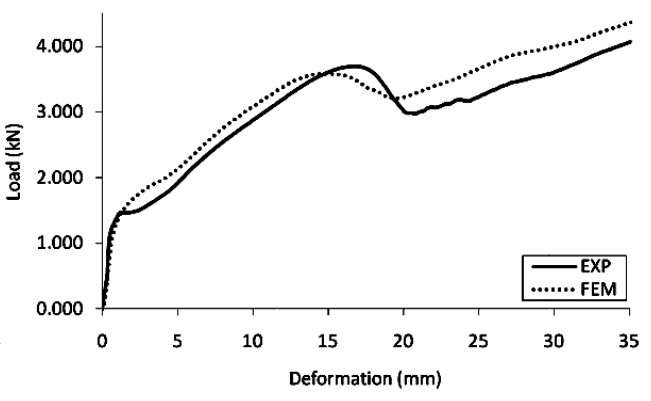

$\mathrm{b}$

Fig. 12. Comparison of the experimental and numerical results for specimen H32-t0.7-a20 in loading with a rigid plate (a) and a rigid tube with a circular cross section (b).

where $F_{\text {perfect }}$ is the mean collapse load for perfect semi-spherical shells without cutouts and $F_{\text {cutout }}$ is the mean collapse load for semi-spherical shells with cutout.

The general form of $K_{\text {cutout }}$ is according to Eq. (2):

$$
K_{\text {cutout }}(\gamma, \lambda)=A+B \gamma+C \gamma^{2}+D \lambda+E \lambda^{2}+F \gamma \lambda+\ldots
$$

The coefficients $A, B, C, \ldots$ are computed using the Lagrangian polynomial method. To use these expressions, the mean collapse load for semi-sherical shells without cutout must be known. 


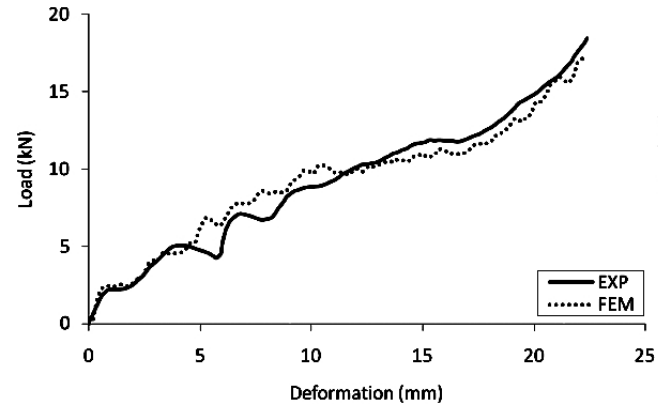

a

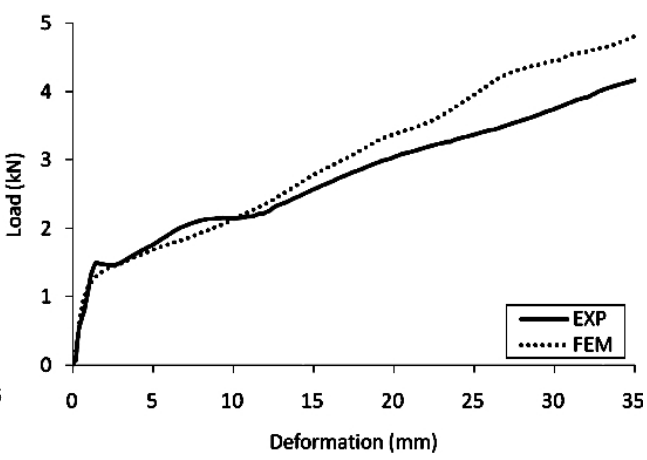

b

Fig. 13. Comparison of the experimental and numerical results for specimen H40-t0.7-a20 in loading with a rigid plate (a) and a rigid tube with a circular cross section (b).

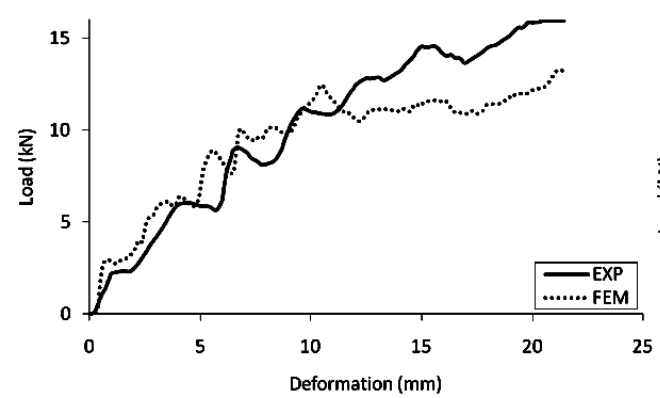

a

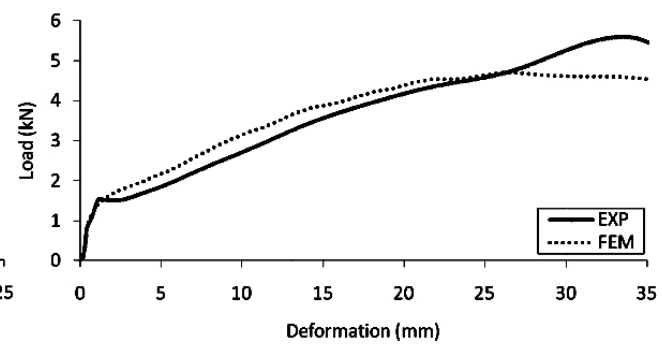

b

Fig. 14. Comparison of the experimental and numerical results for specimen H16-t0.7-a30 in loading with a rigid plate (a) and a rigid tube with a circular cross section (b).

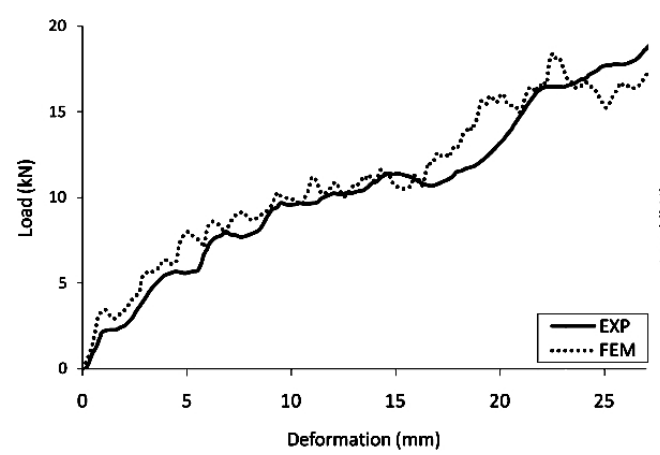

a

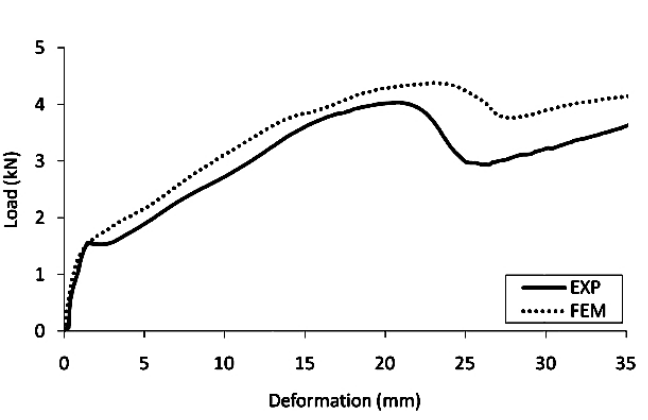

b

Fig. 15. Comparison of the experimental and numerical results for specimen H24-t0.7-a30 in loading with a rigid plate (a) and a rigid tube with a circular cross section (b).

The exact form of the resulting equations is summarized in Eqs. (3)-(6). Both experimental and numerical results (in situations where experimental data were not available) are used in these equations.

$$
17.7807 \lambda^{3}+24.972 \lambda+1217.934 \gamma-39.252 \lambda^{2}-3.97-72115.365 \gamma^{2}+
$$




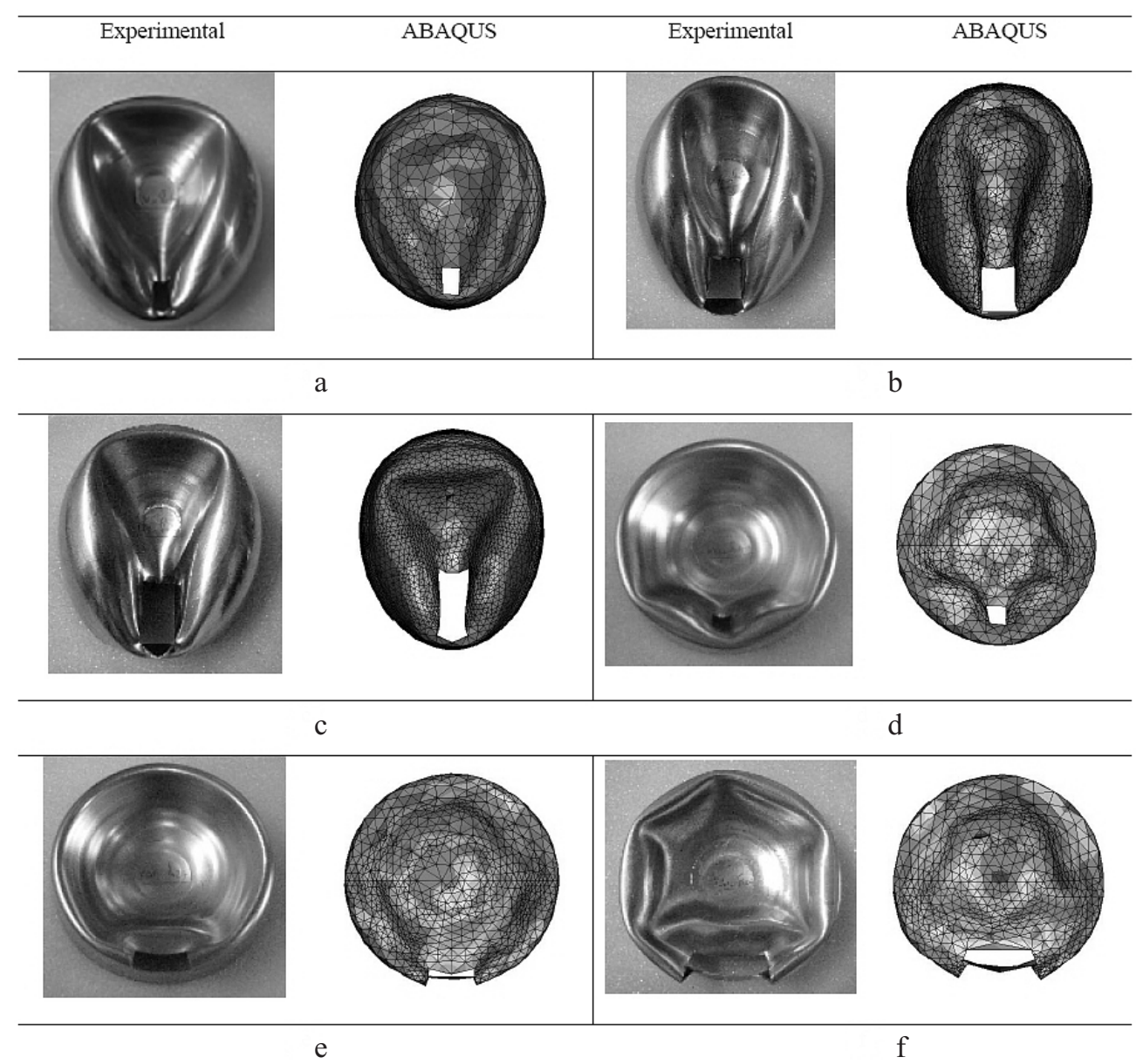

Fig. 16. Comparison of the experimental and numerical results for specimens: (a) H40-t0.7-a10 (CC); (b) H32-t0.7-a20 (CC); (c) H40-t0.7-a20 (CC); (d) H40-t0.7-a10 (RP); (e) H24-t0.7-a20 (RP); (f) H24-t0.7-a30 (RP).

$$
\begin{gathered}
+2.581 \cdot 10^{5} \gamma^{2} \lambda^{3}-5.738 \cdot 10^{5} \gamma^{2} \lambda^{2}+3.705 \cdot 10^{5} \gamma^{2} \lambda-4391.431 \gamma \lambda^{3}+ \\
+9730.298 \gamma \lambda^{2}-6237.407 \gamma \lambda, \\
7.838 \lambda^{3}+21.805 \lambda+1766.218 \gamma-1.007 \cdot 10^{5} \gamma^{2}+1.664 \cdot 10^{5} \gamma^{2} \lambda^{3}- \\
-4.592 \cdot 10^{5} \gamma^{2} \lambda^{2}+3.763 \cdot 10^{5} \gamma^{2} \lambda-2651.85 \gamma \lambda^{3}+7529.321 \gamma \lambda^{2}- \\
-6335.756 \gamma \lambda-5.767-24.187 \lambda^{2}, \\
1.593001715 \lambda^{3}+5.552 \lambda+556.068 \gamma-1.199-5.644 \lambda^{2}-30834.261 \gamma^{2}+ \\
+45637.580 \gamma^{2} \lambda^{3}-1.223 \cdot 10^{5} \gamma^{2} \lambda^{2}+98656.650 \gamma^{2} \lambda-700.8178 \gamma \lambda^{3}+ \\
+1989.794 \gamma \lambda^{2}-1688.249 \gamma \lambda,
\end{gathered}
$$




$$
\begin{gathered}
5.07 \lambda^{3}+19.126 \lambda-1196.966 \gamma+88830.365 \gamma^{2}-8264.288 \gamma^{2} \lambda^{3}- \\
-4479.194 \gamma^{2} \lambda^{2}+34014.989 \gamma^{2} \lambda-362.212 \gamma \lambda^{3}+1592.391 \gamma \lambda^{2}- \\
-2081.485 \gamma \lambda+2.863-17.282 \lambda^{2} .
\end{gathered}
$$

Equations (3) and (4) yield the reduction factor for the semi-spherical shells with the deformation height of $28 \mathrm{~mm}$ and various lengths $(0.006863 \leq t / D \leq 0.011765)$, with a square cutout of fixed side $(a=10)$ and various heights $(0.25 \leq a / H \leq 1.25)$ in different positions of the shell for loading by a rigid plate and a circular cross section bar, respectively.

Equations (5) and (6) yield the same for a square cutout of fixed side $(a=20)$ and various heights $(0.5 \leq a / H \leq 1.25)$.

Conclusions. Semi-spherical shells of different loading with square cutouts of various sizes and positions were investigated experimentally and numerically. The load-deformation curves at different stages of compression are found to match well with those obtained from experiments. The predicted deformed shapes at different stages of compression and various loadings are also found to be in good agreement with the actual deformed profiles. Finally, formulas were presented for the computation of the mean collapse load of semi-spherical shells with square cutouts based on the mean collapse load of perfect semi-spherical shells. These relationships are applicable to a wide range of semi-spherical shells with square cutouts. The following results were found in this study:

1. The mean collapse load is higher in loading by circular bar, in comparison with that by a rigid bar with a spherical cross section.

2. The thickness of shell changes during compression and thickness strain is more in stationary plastic hinges, in comparison to rolling plastic hinges.

3. Rolling plastic hinges increase with increasing of thickness.

4. Among semi-spherical shells of four different thickness values with an identical square cutout, the best geometry, which ensures the maximal value of the mean collapse load under compression conditions, is that with the maximal thickness.

When the cutout side length is constant and height of the cutout increases, the mean collapse load reduces. However, the amount of reduction in the mean collapse load is negligible. Increasing the side length of the cutout while the cutout height is constant decreases the mean collapse load extremely.

\section{Резюме}

Виконано числовий розрахунок втрати стійкості стальних тонкостінних півсферичних оболонок із квадратним вирізом, що знаходяться під дією осьового стиску, i порівняльний аналіз отриманих розрахункових даних з експериментальними. При цьому використано три варіанта прикладання до зразків вертикальних стискальних напружень: через жорстку плоску пластину; через жорстку балку з торцями циліндричної і сферичної форми. Визначався вплив відношень ширини квадратного вирізу до його вертикального положення в оболонці $(a / H)$ і товщини оболонки до іiі діаметра $(t / D)$ на середнє значення критичного навантаження, за якого відбувається втрата стійкості півсферичної оболонки. Скінченноелементні моделі реалізовано за допомогою програмного пакета ABAQUS для нелінійного розрахунку втрати стійкості, а відповідні експериментальні результати отримано з використанням сервогідравлічної випробувальної установки INSTRON 8802. Порівняльний аналіз результатів, отриманих двома розрахунковими методами, показав тісну кореляцію між експериментальними і числовими нелінійними розрахунковими даними. 
1. D. P. Updike, "On the large deformation of a rigid-plastic spherical shell compressed by a rigid plate," J. Manuf. Sci. Eng., 94, No. 3, 949-955 (1972).

2. R. Kitching, R. Houston, and W. Johnson, "A theoretical and experimental study of hemispherical shells subjected to axial loads between flat plates," Int. J. Mech. Sci., 17, 693-703 (1975).

3. J. G. De Oliveira and T. Wierzbicki, "Crushing analysis of rotationally symmetric plastic shells," J. Strain Anal. Eng. Des., 17, No. 4, 229-236 (1982).

4. A. N. Kinkead, A. Jennings, J. Newell, and J. C. Leinster, "Spherical shells in inelastic collision with a rigid wall - tentative analysis and recent quasi static testing," J. Strain Anal. Eng. Des., 29, No. 1, 17-41 (1994).

5. N. K. Gupta, G. L. Easwara Prasad, and S. K. Gupta, "Axial compression of metallic spherical shells between rigid plates," Thin-Walled Struct., 34, No. 1, 21-41 (1999).

6. N. K. Gupta and Venkatesh, "Experimental and numerical studies of dynamic axial compression of thin walled spherical shells," Int. J. Impact Eng., 30, No. 8-9, 1225-1240 (2004).

7. M. Shariati and M. Mahdizadeh Rokhi, "Numerical and experimental investigations on buckling of steel cylindrical shells with elliptical cutout subject to axial compression," Thin-Walled Struct., 46, No. 11, 1251-1261 (2008).

8. M. Shariati and M. Mahdizadeh Rokhi, "Investigation of buckling of steel cylindrical shells with elliptical cutout under bending moment," Int. Rev. Mech. Eng., 3, No. 1, 7-15 (2009).

9. P. K. Gupta and N. K. Gupta, "A study of axial compression of metallic hemispherical domes," J. Mater. Process. Technol., 209, No. 4, 2175-2179 (2009).

10. M. Shariati and M. Mahdizadeh Rokhi, "Buckling of steel cylindrical shells with elliptical cutout," Int. J. Steel Struct., 10, No. 2, 193-205 (2010).

11. M. Shariati and M. Mahdizadeh Rokhi, "Experimental and numerical study of buckling of steel cylindrical shells with quasi elliptical cutout subjected to axial compression load," Amirkabir J. Mech. Eng., 42, No. 1, pp. 1-8 (2010).

12. M. Shariati and H. R. Allahbakhsh, "Numerical and experimental investigations on the buckling of steel semi-spherical shells under various loadings," Thin-Walled Struct., 48, No. 8, 620-628 (2010).

13. ASTM A370-05. Standard Test Methods and Definitions for Mechanical Testing of Steel Products.

14. J. Lee, H. T. Nguyen, and S. E. Kim, "Buckling and post buckling of thin-walled composite columns with intermediate-stiffened open cross-section under axial compression," Int. J. Steel Struct., 9, No. 3, 175-184 (2009).

15. ABAQUS 6.7 PR11 User's Manual.

16. C. F. Gerald and P. O. Wheatley, Applied Numerical Analysis, Addison Wesley, New York (1999). 